\title{
Abl kinase deficiency promotes AKT pathway activation and prostate cancer progression and metastasis
}

\author{
Melissa A Marchal ${ }^{1}$, Devon L Moose ${ }^{2}$, Afshin Varzavand ${ }^{1}$, Destiney Taylor $^{1}$, James A \\ Brown $^{3,4}$, Michael D Henry ${ }^{2,4}$, Christopher S Stipp ${ }^{1,4}$
}

${ }^{1}$ Department of Biology, College of Liberal Arts and Sciences, University of lowa, lowa City lowa. ${ }^{2}$ Department of Molecular Physiology and Biophysics, Carver College of Medicine, University of lowa, lowa City, lowa. ${ }^{3}$ Department of Urology, Carver College of Medicine, University of lowa, lowa City, lowa. ${ }^{4}$ Holden Comprehensive Cancer Center, University of lowa, lowa City, lowa.

Correspondence: christopher-stipp@uiowa.edu

Running title: Abl kinases suppress prostate cancer progression 


\section{Abstract}

2 Abl family kinases function as proto-oncogenes in various leukemias, and pro-tumor functions

3 have been discovered for Abl kinases in solid tumors as well. However, a growing body of

4 evidence indicates that Abl kinases can function to suppress tumor cell proliferation, motility,

5 and in vivo tumor growth in some settings. To investigate the role of Abl kinases in prostate

6 cancer, we generated Abl-deficient cells in a pre-clinical model of spontaneously metastatic,

7 androgen-indifferent prostate cancer. Loss of Abl family kinase expression resulted in a highly

8 aggressive, metastatic phenotype in vivo that was associated with AKT pathway activation,

9 increased growth on 3D collagen matrix, and enhanced cell motility in vitro. Treatment of Abl

10 kinase-expressing cells with the Abl kinase inhibitor imatinib phenocopied the malignant

11 phenotypes observed in Abl-deficient tumor cells. In addition, inhibiting AKT pathway signaling

12 abolished the increased 3D growth of Abl-deficient cells. Our data reveal that Abl family kinases

13 can function as suppressors of prostate cancer progression and metastasis by restraining AKT

14 signaling, a signaling pathway known to be associated with emergence of metastatic castration-

15 resistant prostate cancer. 


\section{Introduction}

3 There will be an estimated 33,330 deaths due to prostate cancer in 2020 due largely to the

4 emergence in patients of metastatic castration-resistant disease (mCRPC) [1]. Most mCRPC

5 that emerges after first line androgen deprivation therapy remains androgen receptor (AR)-

6 driven [2]. As a result, the potent next-generation AR pathway inhibitors (ARPIs) abiraterone

7 and enzalutamide provide clinical benefits to a significant proportion of mCRPC patients [3, 4].

8 Nevertheless, the eventual emergence of mCRPC that resists all currently available ARPIs

9 remains a major clinical challenge.

11 Mechanisms of resistance to ARPIs include AR amplification [5], AR splice variants and point

12 mutations [6-9], and upregulation of the glucocorticoid receptor, which can promote transcription

13 of AR target genes [10]. However, a subset of ARPI-resistant prostate cancers display basal,

14 mesenchymal, squamous, neuroendrocrine (NE)-like, or AR/NE-double negative phenotypes

15 [11-14]. These "AR-indifferent" tumors activate alternative pathways, including neuronal, cell

16 adhesion, epithelial-mesenchymal transition (EMT), and stem cell pathways $[12,13]$. One recent

17 study found evidence of NE-like disease in $17 \%$ of 160 patients whose cancer had progressed

18 on abiraterone or enzalutamide, a feature associated with shorter overall survival [15]. No

19 targeted therapies exist for AR-indifferent mCRPC, thus there is an urgent need to identify

20 clinically actionable targets that promote proliferation and survival of mCRPC cells that no

21 longer rely on AR signaling.

23 Hyperactivation of PI3K/AKT signaling due to PTEN deficiency can promote the development of

$24 \mathrm{mCRPC}[16,17]$, which may be linked mechanistically to reciprocal inhibition between the AR

25 and PI3K/AKT signaling pathways [18-20]. The emerging view is that the PI3K/AKT and AR 
1 signaling pathways mutually inhibit each other, and therapeutic inhibition of either pathway

2 alone leads to compensatory activation of the other pathway. This insight led to a recent clinical

3 trial using the AKT inhibitor ipatasertib in combination with abiraterone in patients with mCRPC,

4 resulting in improved radiographic progression-free survival compared to abiraterone alone,

5 particularly for PTEN-deficient tumors [21]. However, the presence or absence of AR-indifferent

6 or NEPC-like disease was not evaluated in this trial, and the potential utility of targeting AKT

7 signaling specifically in AR-indifferent mCRPC remains to be explored.

8

9 Although Abl kinases can have tumor promoting functions [22], a growing body of evidence

10 indicates that Abl kinases can function to restrain malignant behavior in multiple cancers [23-

11 32]. We previously identified Abl kinases as potential metastasis suppressors operating

12 downstream of $\alpha 3$ integrin in a PTEN-deficient model of mesenchymal, AR-indifferent mCRPC

13 [33]. However, the role of Abl kinases in mCRPC progression and dissemination in vivo was

14 unknown, and the molecular mechanism by which Abl kinases can restrain malignant behaviors

15 of mCRPC cells remained to be defined. We now find that Abl kinase-deficiency dramatically

16 potentiates CRPC progression and metastasis in vivo, which corresponds to upregulation of

17 AKT signaling and tumor cell growth on 3D matrix, and increased tumor cell motility. Our results

18 reveal a novel mechanism by which Abl kinases function to inhibit tumor progression, and

19 support the rationale of targeting AKT signaling in PTEN-deficient, AR-indifferent mCRPC.

\section{Materials and methods}

\section{Cell lines and culture}

23 GS689.Li cells are a metastatic variant of PC-3 prostate cancer cells, that were created by in

24 vivo passaging of PC-3 prostate cancer cells in SCID mice [34], and subsequently reverified by

25 STR analysis (IDEXX Bioresearch) [33]. TEM4-18 cells are a subpopulation of PC-3 prostate 
1 cancer cells selected for enhanced transendothelial migration in vitro [34]. DU-145 cells, LNCaP

2 cells, VCaP cells, and 22Rv1 cells were obtained directly from ATCC. Growth base media and

3 supplements were from Gibco ThermoFisher. GS689.Li cells, TEM4-18 cells, and DU-145 cells

4 were cultured in DMEM:F12, LNCaP cells and 22Rv1 cells were cultured in RPMI, and VCaP

5 cells were cultured in DMEM. Growth media were supplemented with glutamine,

6 penicillin/streptomycin, non-essential amino acids, and 10\% FBS (Atlanta Biologicals). All cell

7 lines harbored a PQCXIN retroviral expression vector encoding luciferase.

8

$9 \quad$ Antibodies and reagents

10 This study utilized antibodies from Cell Signaling Technology against FOXA2 (\#8186), Rb

11 (\#9309), c-ABL (\#2862), FAK (\#3285), SRC (\#2110), phospho-SRC Tyr416 (\#6943), ERK

12 (\#4696), phospho-ERK (\#9101), phospho-AKT Ser473 (\#4060), phospho-AMPKa Thr172

13 (\#2535), Cyclin D3 (\#2936), phospho-S6 Ribosomal Protein Ser240/244 (\#5364), and AXL

14 (\#8661). Also used were antibodies from BD Transduction against E-cadherin (\#610181),

15 phospho-FAK Tyr397 (\#611806), and AKT (\#610860), as well as $\alpha$-tubulin (12G10,

16 Developmental Studies Hybridoma Bank), phospho-AXL Tyr779 (MAB6965, R\&D Systems),

17 chromogranin A (NB100-79914, Novus Biologicals), and ARG (Arg 11, generous gift from

18 Anthony Koleske, PhD, Yale University). Secondary antibodies used were goat-anti-mouse and

19 goat-anti-rabbit antibodies conjugated to Alexa 790, 680, 594, or 488 (Invitrogen). Other

20 reagents were D-luciferin (Gold Biotechnology), rat tail collagen I (Corning \& Advanced

21 Biomatrix), imatinib (Cayman Chemical), and MK-2206 and R428 (Selleckchem).

\section{RNA interference}

24 The specificity and efficacy of $A B L$ and ARG knockdown was previously validated by multiple

25 independent RNAi targeting vectors [33]. We used the most effective RNAi vectors from our

26 previous study to create Abl (ABL KD) and Arg (ARG KD) single and double knockdown 
1 (ABL/ARG KD) GS689.Li cells. The Abl sh3 retroviral construct has a pZIP-mCMV-ZsGreen

2 backbone (Transomics Technologies) and the Arg sh2 retroviral construct has a pSIREN

3 RetroQ vector backbone (Clontech).

4

5 All four cell lines were carefully matched by passage number and contained both vector

6 backbones. Thus, vector controls (NT/NT) contained both non-targeting shRNAs in the

7 corresponding vector backbones, single knockdowns contained one targeting shRNA in one

8 vector backbone and one non-targeting shRNA in the other vector backbone, and double

9 knockdowns contained both targeting shRNAs in the corresponding vector backbones. Because

10 each cell line in the set contained a pZIP-mCMV-ZsGreen vector, all cells were fluorescently

11 labeled. Cells were maintained as stably transduced, polyclonal populations. The RNAi targeting

12 sequences used for the present study were as follows: Abl sh3, 5'-

13 GCAGTCATGAAAGAGATCAAA-3' (ULTRA-3267084, Transomics); and Arg sh2, 5'-

14 CCTCAAACTCGCAACAAAT-3'.

\section{Orthotopic prostate cancer model}

17 All animal protocols were approved by the University of lowa Institutional Animal Care and Use

18 Committee (Approval \#8031328). On the day of inoculation, $5 \times 10^{4} \mathrm{NT} / \mathrm{NT}, \mathrm{ABL}$ KD, ARG KD,

19 and ABL/ARG KD GS689.Li cells were implanted in the left or right anterior lobe of the prostate

20 of $10 \mathrm{SCID/NCr}(\mathrm{BALB} / \mathrm{C})$ mice/cell line. Bioluminescent imaging (BLI) was performed using an

21 Ami X imaging system (Spectral Instruments Imaging) as described previously [33]. Upon

22 sacrifice, livers, kidneys, and lungs were dissected for imaging of disseminated cells by

23 fluorescence microscopy using an Olympus SZX12 stereomicroscope, as described [33].

24 GS689.Li cells from primary tumors were recovered by mincing with a sterile razor blade and

25 digesting with $200 \mathrm{U} / \mathrm{ml}$ collagenase II (Worthington Biochemical Corporation) for 15 min at

$2637^{\circ} \mathrm{C}$. Explanted cells were grown out under G418 to select for luciferase-positive tumor cells. 


\section{Time-lapse motility assays}

3 A total of $2.3 \times 10^{5}$ cells were plated in serum-free medium [SFM; DMEM:F12, supplemented

4 with $5 \mathrm{mg} / \mathrm{mL}$ BSA, glutamine, penicillin/streptomycin, non-essential amino acids, $25 \mathrm{mM}$

5 HEPES pH 7.2, and insulin-transferrin-selenium (ITS)] on 35-mm dishes coated with $10 \mathrm{ug} / \mathrm{mL}$

6 rat tail collagen I. Time-lapse images were acquired as described previously [33], and migration

7 speed and displacement were calculated using the mTrackJ plugin [35]. ImageJ software was

8 used to measure the morphological characteristics of migrating cells (at $t=20$ minutes) by

9 making cell traces using the Freehand selections tool, followed by the Measure (Shape

10 descriptors) command.

\section{Immunostaining}

13 Cells were fixed with $10 \%$ formalin in HBSM (HEPES-buffered saline with $1 \mathrm{mM} \mathrm{MgCl}$ ), rinsed

14 with Tris-buffered saline, then blocked and permeabilized with $0.1 \%$ NP-40 detergent in $10 \%$

15 goat serum prior to exposure to primary antibodies. Primary antibodies were detected with

16 Alexa 488 or 594-labeled secondary antibodies and coverslips were rinsed and mounted in

17 ProLong Gold with DAPI (ThermoFisher Scientific) for fluorescence microscopy.

3D collagen growth assays

20 Twenty-four-well plates were coated with $350 \mu \mathrm{L}$ of rat tail collagen I $(0.8 \mathrm{mg} / \mathrm{mL}$ in DMEM) per

21 well and allowed to polymerize for 45 minutes at $37^{\circ} \mathrm{C}$. A total of $1.5 \times 10^{4}$ cells per well were

22 seeded in $500 \mu \mathrm{L}$ of SFM. After 7-10 days, cell number was quantified by BLI. Six wells per cell

23 type per condition were quantified in each trial. 


\section{Standard growth assays}

2 A total of $1.5 \times 10^{4}$ cells per well were plated in uncoated 24 -well plates in $500 \mu \mathrm{L}$ of standard

3 growth medium. After 4-7 days, cell number was quantified by BLI. Six wells per cell type were

4 quantified in each trial.

$6 \quad$ Immunoblotting

7 Cells were rinsed twice with HBSM and lysed in Laemmli buffer. For analysis of cells growing in

$83 \mathrm{D}$ conditions, cells growing on $0.8 \mathrm{mg} / \mathrm{ml}$ collagen I were rinsed twice with HBSM and then

9 incubated two minutes at room temperature with Laemmli buffer. Lysate was collected from the

10 surface of the 3D matrix by pipetting. Protein concentrations of lysates were normalized using

11 the RED 660 Protein Assay (G Biosciences) prior to SDS-PAGE and immunoblotting. Blots

12 were analyzed using a LiCOR Odyssey blot imager.

14 Reverse phase protein array (RPPA)

15 Cells growing on 3D collagen for 4 days were lysed in $10 \%$ glycerol, $2 \%$ SDS, 0.0625 M Tris-

$16 \mathrm{HCL}, \mathrm{pH} 6.8$, and $2.5 \%$ beta-mercaptoethanol, and lysate concentrations were adjusted to 1.0

$17 \mathrm{ug} / \mathrm{uL}$. Duplicate lysates of NT/NT and ABL/ARG KD cells were analyzed at the Functional

18 Proteomics RPPA core facility (MD Anderson Cancer Center). Normalized linear protein levels

19 for each of 304 signaling proteins included in the analysis were used to calculate the normalized

20 linear fold change [(normalized linear value ABL/ARG KD)/(normalized linear value NT/NT)],

21 and a cutoff was set for an average fold change of 1.2 or greater or 0.8 or less. A heatmap was

22 generated using median centered $\log _{2}$ values from targets meeting the cutoff criteria, using the

23 Heatmapper tool (http://www.heatmapper.ca/). 


\section{Statistics}

2 Statistical analyses were performed using GraphPad Prism Version: 7.02 (GraphPad Software,

3 Inc.) Student's t-test and ANOVA were employed for pairwise and multiple comparisons,

4 respectively. When appropriate, Mann-Whitney Rank Sum and ANOVA on Rank (Kruskal-

5 Wallis) tests were also used.

6

$7 \quad$ Results

8 GS689.Li cells are a model of MCRPC with mesenchymal and neuroendocrine-like

\section{9 features}

10 We previously described the isolation of GS689.Li cells, a metastatic variant of the PC-3

11 prostate carcinoma [34]. As described by other groups [36], we found that cells recovered from

12 the rare metastases that emerge from PC-3 xenografts were more metastatic upon re-injection

13 [34]. Strikingly, these metastatic variants displayed loss of E-cadherin and upregulation of a

14 mesenchymal gene expression program [34]. Since PC-3 cells have been reported to possess

15 NE-like features [37, 38], and EMT and NE phenotypes are intertwined [13], we investigated

16 that interconnection in GS689.Li cells. Both parental PC-3 and GS689.Li cells appeared positive

17 for the NE marker chromogranin A (Fig. S1A, B), as previously reported for parental PC-3 cells

18 [39]. The PC-3 parental cell population is p53-null [40], and dual loss of p53 and Rb can drive

19 an NE-like phenotype [41, 42]. Nevertheless, both PC-3 and GS689.Li cells retain Rb

20 expression (Fig. S1C, D), as previously described for the parental PC-3 cells [43]; however, PC-

213 cells are PTEN-deficient [44], and loss of PTEN or activation of AKT can also contribute to an

22 aggressive phenotype with neuroendocrine features [41, 45]. Recently, transcription factor

23 FOXA2 has been described as a marker for a significant fraction of neuroendocrine-like prostate

24 cancers [37]. We detected a FOXA2-positive subpopulation in the parental PC-3 cell line that

25 corresponded largely to the E-cadherin-negative sub-population in double labeling experiments 
1 (Fig. S1E). Strikingly, 100\% of the GS689.Li cells were E-cadherin-negative/FOXA2-positive,

2 with strong nuclear FOXA2 localization (Fig. S1F). Collectively, these data reveal that parental

3 PC-3 cells already express some features of NE-like CRPC, but that in vivo passaging selected

4 for a metastatic, FOXA2-positive, mesenchymal subpopulation.

\section{Abl kinases function as suppressors of mCRPC tumor progression and metastasis}

7 To investigate the role of the Abl family kinases in mCRPC tumor growth and metastasis, we

8 depleted ABL1 (ABL KD), ABL2 (ARG KD) or both kinases (ABL/ARG KD) in GS689.Li cells.

9 Luciferase/ZsGreen dual-labeled, Abl kinase-deficient and non-targeting control cells (NT/NT),

10 were orthotopically implanted, and in vivo tumor progression was monitored weekly via BLI. By

11 day 35 after implantation, mice harboring $A B L K D$ cells and $A B L / A R G K D$ cells displayed a

12 markedly higher apparent tumor burden than mice harboring ARG KD or NT/NT control cells

13 (Fig. 1A). Across the course of the experiment, Abl kinase-deficient tumors progressed more

14 rapidly than control tumors (Fig. 1B). Loss of $A B L$ had a large effect, but loss of both $A B L$ and

15 ARG had the largest effect, resulting in tumor burdens over an order of magnitude greater than

16 NT/NT control tumors by day 35.

18 To attempt to control for effects of primary tumor size, we allowed mice in the different groups to

19 age out for different times until their total tumor burdens approached a similar value, although

20 the vector control group still had lower average tumor burden at the time of sacrifice. Shown in

21 Fig. 1C are gross necropsy images of mice with NT/NT control, ABL KD, ARG KD, and

22 ABL/ARG KD tumors. The apparent tumor burden of all four mice was $\sim 1 \times 10^{9}$ photons/sec

23 prior to sacrifice, yet the dissemination of Abl kinase-deficient tumor cells appeared qualitatively

24 substantially increased compared to vector control tumor cells (Fig. 1C). Analysis of tumor cells

25 explanted at the time of sacrifice revealed an $80-85 \%$ reduction in Abl and Arg proteins (Fig. 
1 S2), which was similar to what we observed in ABL and ARG KD cells prior to implantation (Fig.

2 1D), demonstrating that $A B L$ and $A R G$ knockdown was maintained in tumor cells in vivo.

4 We used GFP fluorescence microscopy to further investigate tumor cell dissemination to

5 specific organs. ABL KD and ABL/ARG KD tumor cells both displayed significantly increased

6 dissemination to kidney (primarily in the adjacent adrenal gland), liver, and lung compared to

7 vector control cells (Fig. 2A-L, quantified in M-O). For ARG KD single knockdown cells, there

8 was a trend towards increased kidney colonization, although it did not rise to the level of

9 statistical significance in this analysis (Fig. 2M).

11 Because it is difficult to fully account for the contribution of more rapid progression of the

12 primary tumor to increased metastatic dissemination, we also compared the motility of Abl-

13 deficient tumor cells to vector control cells via time lapse video microscopy. ABL/ARG KD cells

14 displayed dramatically increased motility compared to vector control cells, as visualized by cell

15 motility tracks (Fig. 3A), with ABL KD and ARG KD single knockdown cells displaying an

16 intermediate phenotype. Quantification revealed a striking 2-fold increase in migration speed

17 and net displacement of ABL/ARG KD cells compared to vector control cells, with ARG single

18 knockdown producing a larger effect than $A B L$ single knockdown on cell motility. (Fig. 3B, C).

19 The enhanced motility of Abl kinase-deficient cells was associated with a morphological change

20 from round, spread vector control cells to highly polarized Abl kinase-deficient cells, with

21 prominent leading edge lamellipodia (Fig. S3A-D). This morphological change is quantitatively

22 captured as a significant increase in the aspect ratio of ARG KD and ABL/ARG KD cells (Fig.

23 S3E), and a significant reduction in roundness (Fig. S3F).

25 Taken together, these data revealed Abl kinases can function as suppressors of progression

26 and metastatic dissemination of mCRPC cells, restraining tumor growth, metastatic colonization, 
1 and cell motility. Loss of ABL had a larger effect on tumor growth, while loss of ARG had a

2 larger effect on cell motility. These observations may help to explain why loss of both kinases

3 produced the most aggressive phenotype in the in vivo tumor progression model.

6 growth of androgen-indifferent mCRPC cells

7 To begin to investigate the molecular basis of increased tumor growth of Abl kinase-deficient

8 cells, we examined low anchorage growth on a soft 3D collagen matrix, an assay that aligns

9 with the in vivo behavior of our mCRPC model [33]. Similar to the tumor growth in vivo,

10 ABL/ARG KD cells displayed dramatically enhanced 3D growth compared to vector control

11 cells, with $A B L$ single knockdown producing a larger effect than ARG single knockdown (Fig.

12 4A). These differences were context specific, and largely not observed under standard tissue

13 culture conditions (Fig. 4B). We found no major changes in focal adhesion kinase (FAK), Src

14 kinase, or ERK kinase activation among the four cell types growing on 3D matrix (Fig. S4).

15 However, Abl-deficient cells displayed a prominent increase in AKT activation, in a pattern that

16 aligned with their 3D growth. ABL/ARG KD cells had the highest level of AKT activation,

17 followed by ABL single knockdown cells and ARG single knockdown cells (Fig. 4C).

18 Quantification of activated pAKT S473 revealed an $\sim 3.9$-fold increase in ABL/ARG KD cells, and

19 2.2-fold and 1.4-fold increase in ABL and ARG single knockdown cells respectively, relative

20 to NT/NT vector control cells. Under standard tissue culture conditions, all four cell lines

21 displayed similar levels of AKT activation, consistent with their similar growth under those

22 conditions (Fig. 4D).

23

24 We next utilized pharmacological manipulation in conjunction with our 3D growth assay and

25 immunoblot analysis. We predicted that if increased pAKT S473 in ABL KD and ABL/ARG KD

26 cells growing in $3 \mathrm{D}$ is a direct result of $\mathrm{Abl}$ kinase depletion, then imatinib treatment should 
1 produce a large fold change in the growth and phosphorylation of AKT at S473 of non-targeting

2 vector control cells, compared to the fold change for imatinib-treated ABL/ARG KD cells, with

3 much less $A B L$ and $A R G$ protein expression. When we treated Abl family kinase-depleted

$4 \quad \mathrm{mCRPC}$ cells growing in 3D with imatinib, we saw significant increases in growth for all cell

5 types relative to their DMSO controls at both $3 \mathrm{uM}$ and $10 \mathrm{uM}$ imatinib, with the higher dose

6 generating an even greater response (Fig. 5A). The fact that ABL/ARG KD cells still displayed

7 increased 3D growth upon treatment with imatinib mostly likely reflects inhibition of residual

8 amounts of ABL (15\%) and ARG (20\%) remaining in these cells. As anticipated, NT/NT cells

9 experienced the greatest fold change in growth compared to all other cell types at both doses of

10 imatinib, and ABL/ARG KD cells exhibited the smallest fold change in growth, with single

11 knockdown cells displaying an intermediate phenotype (Fig. 5B). In parallel with its ability to

12 promote 3D growth, imatinib treatment dramatically increased phospho-AKT S473 in vector

13 control cells and ARG single knockdown cells, but had minimal to no effect on ABL and

14 ABL/ARG KD cells, in which phospho-AKT levels were already very high (Fig. 5C).

16 To evaluate the generality of the link between Abl kinase signaling and 3D growth of prostate

17 cancer cells, we tested the effect of imatinib on the 3D growth of 5 additional prostate cancer

18 cell lines. DU145 cells and TEM4-18, another derivative of PC-3 cells [34], are androgen

19 indifferent, while LNCaP, 22Rv1, and VCaP are androgen-responsive cell lines. We found that

20 imatinib promoted the 3D growth of the androgen indifferent cell lines to a significantly greater

21 extent than the androgen responsive cell lines, on which it had little or no effect (Fig. 5D).

23 To determine the extent to which AKT signaling is required for the increased 3D growth of Abl

24 kinase-deficient cells, we treated cells with increasing doses of the AKT inhibitor MK-2206. MK-

252206 abolished the 3D growth of all 4 cell types, even the ABL/ARG KD cells with the highest

26 level of 3D growth (Fig. 6A), and extinguished active AKT in the cells (Fig. 6B). In contrast, 
1 under standard culture conditions, the same doses of MK-2206 slowed but did not abolish cell

2 proliferation (Fig. 6C). Together with the previous data, these results indicate that one major

3 consequence of Abl kinase deficiency is to promote AKT signaling, which can result in

4 increased 3D growth of androgen-indifferent prostate cancer cells.

5

6 Reverse phase protein array (RPPA) analysis reveals upstream and downstream

7 effectors of AKT signaling in Abl kinase-deficient mCRPC cells

8 To investigate the link between Abl family kinases and AKT signaling we generated lysates of

9 NT/NT and ABL/ARG KD cells growing in 3D conditions for analysis by RPPA using 304

10 antibodies to cancer-relevant signaling proteins. An arbitrary cut off was set for an average fold

11 change of 1.2 or 0.8 . Antibodies with average fold changes meeting the cutoff criteria were

12 visualized by a heatmap using median centered normalized $\log _{2}$ values (Fig. 7A; see Table S1

13 for full results of the RPPA).

As expected, pAKT S473 (fold change = 1.5; black arrow Fig. 7A) and c-ABL (fold change = 0.7; red arrow Fig. 7A) were among the list of 64 differentially expressed antigens (DEAs).

Additionally, several canonical AKT signaling components were differentially expressed (selected list in Fig. 7B). Pathway analysis with DAVID showed that $26.3 \%$ of DEAs were associated with the PI3K-AKT signaling pathway $\left(P=6.7 \times 10^{-8}\right)$. Cell cycle factors were also greatly enriched in DEAs (selected list in Fig. 7C), with DAVID pathway analysis showing 15.8\% being associated with the cell cycle $\left(P=2.2 \times 10^{-6}\right)$. Proteins involved in metabolism and lipogenesis (selected list in Fig. 7D) were also prevalent among DEAs and $15.8 \%$ of them were associated with AMPK signaling (DAVID pathway analysis; $P=2.2 \times 10^{-6}$ ).

We further validated our RPPA data by immunoblotting proteins from each of the categories identified during DAVID pathway analysis (Fig. S5). Expression of the canonical AKT signaling 
1 target S6 Ribosomal Protein phosphorylated at serine 240/244 (pS6 S240/244) (Fig. S5A, D),

2 and cyclin D3 (Fig. S5B, E), mirrored the pattern of pAKT S473 expression in Abl family kinase-

3 depleted cells, with the highest expression levels of these antigens in ABL/ARG KD double

4 knockdown and ABL KD single knockdown cells. Conversely, expression of AMPKa

5 phosphorylated at its activating threonine172, a site negatively regulated by AKT [46], was

6 downregulated in ABL/ARG KD cells (Fig. S5C, F).

7

$8 \mathrm{AXL}$, a receptor tyrosine kinase and known activator of PI3K/AKT signaling [47], was also

9 among the DEAs identified in our RPPA dataset. Therefore, we assessed expression of total

$10 \mathrm{AXL}$, as well as expression of an autophosphorylation site at tyrosine 779 (pAXL Y779) known

11 to bind the p85a and p85 $\beta$ subunits of PI3K [47]. Both phospho-AXL and total AXL levels were

12 increased in the $A B L$ single knockdown and ABL/ARG double knockdown cells relative to

13 NT/NT vector control cells. Quantification revealed an $\sim 1.2$ fold increase pAXL Y779 in ABL

14 single knockdown cells and $\sim 1.4$ fold increase in ABL/ARG double knockdown cells, while

15 expression of total AXL was substantially higher in ABL KD cells ( 2.3 fold increase) and

16 ABL/ARG KD cells ( 3.3 fold increase) (Fig. 8A). Moreover, pharmacological inhibition of Abl

17 kinase activity in NT/NT cells using imatinib led to an $~ 1.4$-fold increase in total AXL expression

18 in cells growing on 3D matrix (Fig. S6).

20 To investigate whether increased AXL expression in Abl-deficient cells contributes to AKT

21 activation and 3D growth, we treated cells with the specific AXL inhibitor, R428 (BGB324) [48].

22 R428 strongly suppressed the 3D growth of Abl-deficient cells (Fig. 8B) and partially canceled

23 the increased AKT activation seen in ABL kinase single knockdown and ABL/ARG double

24 knockdown cells (Fig. 8C). Taken together, results of our RPPA analysis and subsequent

25 validation studies solidify AKT activation as a major pro-tumor outcome of Abl kinase deficiency 
1 and identify increased AXL expression as a candidate mediator of increased AKT signaling and

$23 \mathrm{D}$ growth of Abl kinase-deficient cells.

3

4 Discussion

5 A major finding of our study was the dramatic increase in the rate of tumor progression and

Although inhibiting Abl kinase activity has been advanced as potential therapeutic strategy for treating solid tumors [22], our new results add to a growing number of studies that point to the ability of Abl kinases to suppress cell motility, promote apoptosis, and negatively regulate cell

proliferation and tumor progression in multiple settings [23, 26-29, 32, 51-55]. Anti-tumor activity of Abl kinases has been linked to signaling by tumor suppressor EphB4 [29], p53-P21 signaling $[23,27,55]$, negative regulation of Ras-MAP kinase signaling [26], and conversion of the protooncogenic YAP1 transcription factor from a pro-growth to a pro-apoptotic function upon DNA damage [54]. Our new data point to additional anti-tumor functions for Abl kinases that are distinct from those that have previously been described. We find that Abl family kinase depletion results in a dramatic upregulation of AKT pathway signaling in our p53-null, PTEN-deficient mCRPC model, with no obvious impact on signaling via the MAP kinase pathway (Figure S4). Pre-clinical data 
1 link hyperactivation of the AKT pathway to the emergence of mCRPC [16-20], but our new data

2 suggest that AKT signaling can continue to sustain the 3D growth of fully AR-indifferent mCRPC

3 cells. Moreover, our data support the view that even in the context of PTEN deficiency other

4 factors, such as Abl family kinase signaling, can continue to restrain the full oncogenic capacity

5 of the AKT pathway.

6

7 The mechanism by which Abl kinase deficiency results in upregulation of the AKT pathway

8 requires further study. However, our RPPA data nominated increased protein expression of the

9 receptor tyrosine kinase $A X L$ as one major input into the increased AKT signaling in Abl-

10 deficient cells. In prostate cancer, AXL signaling has been associated with metformin, taxotere,

11 and docetaxel resistance [56-58], as well as EMT-like events, increased migration and invasion,

12 proliferation and tumor growth [59-61]. Conversely, some studies have reported anti-proliferative

13 effects for $A X L$, which may be related to its ability to induce tumor cell dormancy in some

14 settings [58, 62]. AXL has also recently emerged as a direct target of tumor suppressive micro-

15 RNAs in prostate cancer models [63, 64].

17 The new findings presented here have important implications for ongoing clinical efforts to target

18 AKT in mCRPC, such as the phase III trial combining AKT inhibitor ipatasertib with abiraterone

19 (NCT03072238). The scientific rationale for this combination trial involves reciprocal feedback

20 between androgen receptor signaling and PI 3-kinase/Akt signaling in PTEN-deficient prostate

21 cancer [21], such that inhibiting one pathway activates the other, suggesting dual inhibition as a

22 strategy. However, this clinical trial is not designed to investigate efficacy related to the

23 presence or absence of AR-indifferent and neuroendocrine-like disease and also will not

24 address the potential utility of AKT inhibition in mCRPC that has already progressed to an AR-

25 indifferent state. Our data suggest the possibility that tumors that evolve resistance to AR

26 inhibitors such as abiraterone yet remain AR-driven may be less amenable to AKT inhibitors 
1 than tumors that evolve to an AR-indifferent state. Important future directions based on results

2 presented here include testing the efficacy of AKT and AXL inhibitors in pre-clinical in vivo

3 models of AR-indifferent and AR-driven metastatic prostate cancer and investigating at the

4 protein level AXL and AKT expression and markers of Abl kinase activity in mCRPC clinical

5 specimens. It will also be important to investigate the mechanism by which Abl kinase deficiency

6 results in upregulation of $A X L$ protein and the extent to which factors in addition to $A X L$

7 expression contribute to AKT pathway hyperactivation in Abl deficient cells. Such investigations

8 may yield additional treatment strategies for AR-indifferent, NE-like prostate cancers, especially

9 those with PTEN deficiency, which represents $\sim 50-60 \%$ of all NE-like mCRPC [13].

\section{Acknowledgements}

12 Dr. Brown is the current University of lowa Andersen-Hebbeln Professor in Prostate Cancer

13 Research. This endowed professorship provided financial support related to this research effort.

14 Core facilities used in these studies were supported by NIH grant P30 CA086862.

\section{Competing interests}

17 None to disclose. 


\section{References}

1 Siegel RL, Miller KD, Jemal A. Cancer statistics, 2020. CA Cancer J Clin 2020; 70: 7-30.

2 Watson PA, Arora VK, Sawyers CL. Emerging mechanisms of resistance to androgen receptor inhibitors in prostate cancer. Nature reviews Cancer (Review) 2015; 15: 701711.

3 de Bono JS, Logothetis CJ, Molina A, Fizazi K, North S, Chu L et al. Abiraterone and increased survival in metastatic prostate cancer. The New England journal of medicine (Clinical Trial, Phase III) 2011; 364: 1995-2005.

4 Scher HI, Fizazi K, Saad F, Taplin M-E, Sternberg CN, Miller K et al. Increased survival with enzalutamide in prostate cancer after chemotherapy. The New England journal of medicine (Clinical Trial, Phase III) 2012; 367: 1187-1197.

5 Visakorpi T, Hyytinen E, Koivisto P, Tanner M, Keinänen R, Palmberg C et al. In vivo amplification of the androgen receptor gene and progression of human prostate cancer. Nature genetics 1995; 9: 401-406.

6 Dehm SM, Schmidt LJ, Heemers HV, Vessella RL, Tindall DJ. Splicing of a novel androgen receptor exon generates a constitutively active androgen receptor that mediates prostate cancer therapy resistance. Cancer Research 2008; 68: 5469-5477.

7 Li Y, Chan SC, Brand U, Hwang TH, Silverstein KAT, Dehm SM. Androgen receptor splice variants mediate enzalutamide resistance in castration-resistant prostate cancer cell lines. Cancer Research 2013; 73: 483-489.

8 Tan J, Sharief Y, Hamil KG, Gregory CW, Zang DY, Sar M et al. Dehydroepiandrosterone activates mutant androgen receptors expressed in the androgen-dependent human prostate cancer xenograft CWR22 and LNCaP cells. Molecular endocrinology (Baltimore, Md) (Comparative Study) 1997; 11: 450-459.

9 Veldscholte J, Ris-Stalpers C, Kuiper GG, Jenster G, Berrevoets C, Claassen E et al. A mutation in the ligand binding domain of the androgen receptor of human LNCaP cells affects steroid binding characteristics and response to anti-androgens. Biochemical and biophysical research communications 1990; 173: 534-540.

10 Arora VK, Schenkein E, Murali R, Subudhi SK, Wongvipat J, Balbas MD et al. Glucocorticoid receptor confers resistance to antiandrogens by bypassing androgen receptor blockade. Cell 2013; 155: 1309-1322. 
11 Beltran H, Prandi D, Mosquera J-M, Benelli M, Puca L, Cyrta J et al. Divergent clonal evolution of castration-resistant neuroendocrine prostate cancer. Nature medicine 2016; 22: 298-305.

12 Labrecque MP, Coleman IM, Brown LG, True LD, Kollath L, Lakely B et al. Molecular profiling stratifies diverse phenotypes of treatment-refractory metastatic castrationresistant prostate cancer. J Clin Invest 2019; 130: 4492-4505.

13 Puca L, Vlachostergios PJ, Beltran H. Neuroendocrine Differentiation in Prostate Cancer: Emerging Biology, Models, and Therapies. Cold Spring Harbor perspectives in medicine (Review) 2019; 9: a030593.

14 Smith BA, Sokolov A, Uzunangelov V, Baertsch R, Newton Y, Graim K et al. A basal stem cell signature identifies aggressive prostate cancer phenotypes. Proceedings of the National Academy of Sciences of the United States of America 2015; 112: E6544-6552.

15 Aggarwal R, Huang J, Alumkal JJ, Zhang L, Feng FY, Thomas GV et al. Clinical and Genomic Characterization of Treatment-Emergent Small-Cell Neuroendocrine Prostate Cancer: A Multi-institutional Prospective Study. Journal of clinical oncology : official journal of the American Society of Clinical Oncology 2018; 36: 2492-2503.

16 Jiao J, Wang S, Qiao R, Vivanco I, Watson PA, Sawyers CL et al. Murine cell lines derived from Pten null prostate cancer show the critical role of PTEN in hormone refractory prostate cancer development. Cancer Res 2007; 67: 6083-6091.

17 Wang S, Gao J, Lei Q, Rozengurt N, Pritchard C, Jiao J et al. Prostate-specific deletion of the murine Pten tumor suppressor gene leads to metastatic prostate cancer. Cancer Cell 2003; 4: 209-221.

18 Carver BS, Chapinski C, Wongvipat J, Hieronymus H, Chen Y, Chandarlapaty S et al. Reciprocal feedback regulation of PI3K and androgen receptor signaling in PTENdeficient prostate cancer. Cancer Cell 2011; 19: 575-586.

19 Jia S, Gao X, Lee SH, Maira S-M, Wu X, Stack EC et al. Opposing effects of androgen deprivation and targeted therapy on prostate cancer prevention. Cancer discovery 2013; 3: 44-51.

20 Mulholland DJ, Tran LM, Li Y, Cai H, Morim A, Wang S et al. Cell autonomous role of PTEN in regulating castration-resistant prostate cancer growth. Cancer Cell 2011; 19: 792-804.

21 de Bono JS, De Giorgi U, Rodrigues DN, Massard C, Bracarda S, Font A et al. Randomized Phase II Study Evaluating Akt Blockade with Ipatasertib, in Combination with Abiraterone, in Patients with Metastatic Prostate Cancer with and without PTEN Loss. 
Clinical cancer research : an official journal of the American Association for Cancer Research 2019; 25: 928-936.

22 Greuber EK, Smith-Pearson P, Wang J, Pendergast AM. Role of ABL family kinases in cancer: from leukaemia to solid tumours. Nature reviews Cancer (Review) 2013; 13: 559571.

23 Allington TM, Galliher-Beckley AJ, Schiemann WP. Activated Abl kinase inhibits oncogenic transforming growth factor-beta signaling and tumorigenesis in mammary tumors. The FASEB journal : official publication of the Federation of American Societies for Experimental Biology 2009; 23: 4231-4243.

24 Aloisi A, Di Gregorio S, Stagno F, Guglielmo P, Mannino F, Sormani MP et al. BCR-ABL nuclear entrapment kills human CML cells: ex vivo study on 35 patients with the combination of imatinib mesylate and leptomycin B. Blood 2006; 107: 1591-1598.

25 Dasgupta Y, Koptyra M, Hoser G, Kantekure K, Roy D, Gornicka B et al. Normal ABL1 is a tumor suppressor and therapeutic target in human and mouse leukemias expressing oncogenic ABL1 kinases. Blood 2016; 127: 2131-2143.

26 Gil-Henn H, Patsialou A, Wang Y, Warren MS, Condeelis JS, Koleske AJ. Arg/Abl2 promotes invasion and attenuates proliferation of breast cancer in vivo.2013; 32: 26222630.

27 Morrison CD, Allington TM, Thompson CL, Gilmore HL, Chang JC, Keri RA et al. c-Abl inhibits breast cancer tumorigenesis through reactivation of p53-mediated p21 expression. Oncotarget 2016; 7: 72777-72794.

28 Ng KY, Yin T, Machida K, Wu Yl, Mayer BJ. Phosphorylation of Dok1 by Abl family kinases inhibits Crkl transforming activity. Oncogene 2015; 34: 2650-2659.

29 Noren NK, Foos G, Hauser CA, Pasquale EB. The EphB4 receptor suppresses breast cancer cell tumorigenicity through an Abl-Crk pathway. Nature cell biology 2006; 8: 815825.

30 Qiang X-F, Zhang Z-W, Liu Q, Sun N, Pan L-L, Shen J et al. miR-20a promotes prostate cancer invasion and migration through targeting ABL2. Journal of cellular biochemistry 2014; 115: 1269-1276.

31 Vigneri P, Wang JY. Induction of apoptosis in chronic myelogenous leukemia cells through nuclear entrapment of BCR-ABL tyrosine kinase. Nat Med 2001; 7: 228-234. 
32 Zheng J, Machida K, Antoku S, Ng KY, Claffey KP, Mayer BJ. Proteins that bind the Src homology 3 domain of Crkl have distinct roles in Crk transformation. Oncogene 2010; 29: 6378-6389.

33 Varzavand A, Hacker W, Ma D, Gibson-Corley K, Hawayek M, Tayh OJ et al. $\alpha 3 \beta 1$ Integrin Suppresses Prostate Cancer Metastasis via Regulation of the Hippo Pathway. Cancer Research 2016; 76: 6577-6587.

34 Drake JM, Strohbehn G, Bair TB, Moreland JG, Henry MD. ZEB1 Enhances Transendothelial Migration and Represses the Epithelial Phenotype of Prostate Cancer Cells. Molecular biology of the cell 2009; 20: 2207-2217.

35 Meijering E, Dzyubachyk O, Smal I. Methods for cell and particle tracking. Methods Enzymol 2012; 504: 183-200.

36 Pettaway CA, Pathak S, Greene G, Ramirez E, Wilson MR, Killion JJ et al. Selection of highly metastatic variants of different human prostatic carcinomas using orthotopic implantation in nude mice. Clinical cancer research : an official journal of the American Association for Cancer Research 1996; 2: 1627-1636.

37 Park JW, Lee JK, Witte ON, Huang J. FOXA2 is a sensitive and specific marker for small cell neuroendocrine carcinoma of the prostate. Modern pathology : an official journal of the United States and Canadian Academy of Pathology, Inc 2017; 30: 1262-1272.

38 Tai S, Sun Y, Squires JM, Zhang H, Oh WK, Liang C-Z et al. PC3 is a cell line characteristic of prostatic small cell carcinoma. The Prostate (Comparative Study) 2011; 71: 16681679.

39 Leiblich A, Cross SS, Catto JW, Pesce G, Hamdy FC, Rehman I. Human prostate cancer cells express neuroendocrine cell markers PGP 9.5 and chromogranin A. Prostate 2007; 67: 1761-1769.

40 Carroll AG, Voeller HJ, Sugars L, Gelmann EP. p53 oncogene mutations in three human prostate cancer cell lines. The Prostate 1993; 23: 123-134.

41 Ku S-Y, Rosario S, Wang Y, Mu P, Seshadri M, Goodrich ZW et al. Rb1 and Trp53 cooperate to suppress prostate cancer lineage plasticity, metastasis, and antiandrogen resistance. Science (New York, NY) 2017; 355: 78-83.

42 Mu P, Zhang Z, Benelli M, Karthaus WR, Hoover E, Chen C-C et al. SOX2 promotes lineage plasticity and antiandrogen resistance in TP53- and RB1-deficient prostate cancer. Science (New York, NY) 2017; 355: 84-88. 
43 Tan HL, Sood A, Rahimi HA, Wang W, Gupta N, Hicks J et al. Rb loss is characteristic of prostatic small cell neuroendocrine carcinoma. Clin Cancer Res 2014; 20: 890-903.

44 Vlietstra RJ, van Alewijk DC, Hermans KG, van Steenbrugge GJ, Trapman J. Frequent inactivation of PTEN in prostate cancer cell lines and xenografts. Cancer Research 1998; 58: $2720-2723$.

45 Lee JK, Phillips JW, Smith BA, Park JW, Stoyanova T, McCaffrey EF et al. N-Myc Drives Neuroendocrine Prostate Cancer Initiated from Human Prostate Epithelial Cells. Cancer Cell 2016; 29: 536-547.

46 Hawley SA, Ross FA, Gowans GJ, Tibarewal P, Leslie NR, Hardie DG. Phosphorylation by Akt within the ST loop of AMPK-alpha1 down-regulates its activation in tumour cells. Biochem J 2014; 459: 275-287.

47 Braunger J, Schleithoff L, Schulz AS, Kessler H, Lammers R, Ullrich A et al. Intracellular signaling of the Ufo/Axl receptor tyrosine kinase is mediated mainly by a multi-substrate docking-site. Oncogene 1997; 14: 2619-2631.

48 Holland SJ, Pan A, Franci C, Hu Y, Chang B, Li W et al. R428, a selective small molecule inhibitor of Axl kinase, blocks tumor spread and prolongs survival in models of metastatic breast cancer. Cancer Res 2010; 70: 1544-1554.

49 Jachetti E, Rigoni A, Bongiovanni L, Arioli I, Botti L, Parenza M et al. Imatinib Spares cKitExpressing Prostate Neuroendocrine Tumors, whereas Kills Seminal Vesicle EpithelialStromal Tumors by Targeting PDGFR- $\beta$. Molecular cancer therapeutics 2017; 16: 365375.

50 Rosenberg A, Mathew P. Imatinib and prostate cancer: lessons learned from targeting the platelet-derived growth factor receptor. Expert opinion on investigational drugs (Review) 2013; 22: 787-794.

51 Frasca F, Vigneri P, Vella V, Vigneri R, Wang JY. Tyrosine kinase inhibitor STI571 enhances thyroid cancer cell motile response to Hepatocyte Growth Factor. Oncogene 2001; 20: 3845-3856.

52 Kain KH, Gooch S, Klemke RL. Cytoplasmic c-Abl provides a molecular 'Rheostat' controlling carcinoma cell survival and invasion. Oncogene 2003; 22: 6071-6080.

53 Kain $\mathrm{KH}$, Klemke RL. Inhibition of cell migration by Abl family tyrosine kinases through uncoupling of Crk-CAS complexes. The Journal of biological chemistry 2001; 276: 1618516192. 
54 Keshet R, Reuven N, Shaul Y. c-Abl forces YAP to switch sides. Mol Cell Oncol 2015; 2: e995006.

55 Morrison CD, Chang JC, Keri RA, Schiemann WP. Mutant p53 dictates the oncogenic activity of c-Abl in triple-negative breast cancers. Cell death \&amp; disease 2017; 8: e2899-e2899.

56 Bansal N, Mishra PJ, Stein M, Dipaola RS, Bertino JR. AxI receptor tyrosine kinase is upregulated in metformin resistant prostate cancer cells. Oncotarget 2015; 6: 1532115331.

57 Lin J-Z, Wang Z-J, De W, Zheng M, Xu W-Z, Wu H-F et al. Targeting AXL overcomes resistance to docetaxel therapy in advanced prostate cancer. Oncotarget 2017; 8: 41064-41077.

58 Shiozawa Y, Pedersen EA, Patel LR, Ziegler AM, Havens AM, Jung Y et al. GAS6/AXL axis regulates prostate cancer invasion, proliferation, and survival in the bone marrow niche. Neoplasia 2010; 12: 116-127.

59 Mishra A, Wang J, Shiozawa Y, McGee S, Kim J, Jung Y et al. Hypoxia stabilizes GAS6/AxI signaling in metastatic prostate cancer. Mol Cancer Res 2012; 10: 703-712.

60 Paccez JD, Vasques GJ, Correa RG, Vasconcellos JF, Duncan K, Gu X et al. The receptor tyrosine kinase $\mathrm{Axl}$ is an essential regulator of prostate cancer proliferation and tumor growth and represents a new therapeutic target. Oncogene (Research) 2013; 32: 689698.

61 Sainaghi PP, Castello L, Bergamasco L, Galletti M, Bellosta P, Avanzi GC. Gas6 induces proliferation in prostate carcinoma cell lines expressing the Axl receptor. J Cell Physiol 2005; 204: 36-44.

62 Axelrod HD, Valkenburg KC, Amend SR, Hicks JL, Parsana P, Torga G et al. AXL is a Putative Tumor Suppressor and Dormancy Regulator in Prostate Cancer. Molecular cancer research : MCR 2018: molcanres.0718.2018.

63 Nam RK, Benatar T, Wallis CJD, Kobylecky E, Amemiya Y, Sherman C et al. MicroRNA-139 is a predictor of prostate cancer recurrence and inhibits growth and migration of prostate cancer cells through cell cycle arrest and targeting IGF1R and AXL. Prostate 2019; 79: 1422-1438.

64 Paccez JD, Duncan K, Sekar D, Correa RG, Wang Y, Gu X et al. Dihydroartemisinin inhibits prostate cancer via JARID2/miR-7/miR-34a-dependent downregulation of Axl.

Oncogenesis 2019; 8: 14. 


\section{Figure Legends}

Figure 1: Loss of Abl family kinase expression promotes in vivo mCRPC tumor progression and metastatic dissemination

(A) Representative bioluminescence (BLI) images of orthotopic tumors in mice implanted with Abl family kinase-deficient (ABL KD, ARG KD, and ABL/ARG KD) and non-targeting (NT/NT) mCRPC cells at 35 days post-implantation. (B) Semi-log plot depicting average tumor burden (log of photon flux [photons/s]) over time (day) for mice bearing NT/NT (blue line), ABL KD (green line), ARG KD (orange line) and ABL/ARG KD (red line) tumors. Data points indicate mean $+/$ - SEM for $\geq 7$ mice/cell type. ${ }^{*},{ }^{* *},{ }^{* * *}$, and ${ }^{* * * *}$ signify statistically significant $p$-values of $<0.05,<0.01,<0.001$, and $<0.0001$, respectively. Kruskal Wallis with Dunn's multiple comparison test and Mann Whitney test at $\alpha=0.05$. (C) Representative images of BLI-assisted gross necropsies performed immediately after sacrifice for mice harboring NT/NT (sacrificed day 63), ABL KD (sacrificed day 52), ARG KD (sacrificed day 59), and ABL/ARG KD (sacrificed day 45) tumors. PT: primary tumor; Kid: kidney; Li: liver; Lu: lung. (D) Immunoblot analysis of ABL and ARG proteins in all mCRPC cell types prior to implantation. \% values represent blot intensities normalized by an $\alpha$-tubulin loading control and expressed as percent relative to NT/NT. Color scales in A. and C. indicate photons $/ \mathrm{sec} / \mathrm{cm}^{2} / \mathrm{sr}$.

\section{Figure 2: Abl kinase-deficient tumor cells exhibit enhanced metastatic colonization}

Representative fluorescent micrographs of kidneys ( $1^{\text {st }}$ column), livers ( $2^{\text {nd }}$ column), and lungs $\left(3^{\text {rd }}\right.$ column) colonized by GFP-labeled NT/NT (A, B, \& C), ABL KD (D, E, \& F), ARG KD (G, H, \& I), and ABL/ARG KD (J, K, \& L) mCRPC cells. Quantification of kidney (M), liver ( $\mathbf{N})$, and lung (O) colonization as the percentage of total surface area occupied by GFP-labeled mCRPC cells. Bars in $\mathrm{M}, \mathrm{N}, \& \mathrm{O}$ indicate mean $+/-\mathrm{SEM}$ for $\geq 5$ organs/cell type. * and ${ }^{* *}$ in $\mathrm{M}, \mathrm{N}, \& \mathrm{O}$ denote 
statistically significant $p$-values of $<0.05$ and $<0.01$, respectively, and n.s. stands for not significant. Kruskal-Wallis with Dunn's multiple comparison test, $\alpha=0.05$.

Figure 3: The Abl family kinases act to constrain the motility phenotypes of mCRPC cells Abl family kinase-deficient (ABL KD, ARG KD, and ABL/ARG KD) and non-targeting (NT/NT) mCRPC cells were plated on 2D collagen I and had their migration monitored via time-lapse microcopy for 90 minutes. (A) Motility tracks; $n=20$ tracks/cell type. $X / Y$ axes in um, 0 represents point of origin. (B) Graph of average migration speed (um/hr.), $n=>34$ cells/cell type. (C) Graph of average displacement (um) from point of origin, $n=>34$ cells/cell type. Bars in B \& C indicate mean +/- SEM. * and ${ }^{* * * *}$ in B \& C indicate statistically significant $p$-values of < 0.05 and $<0.0001$, respectively, and n.s. stands for not significant. One-way ANOVA w/ Dunnett's multiple comparison, $\alpha=0.05$.

Figure 4: Increased AKT activation and 3D growth of $\mathrm{mCRPC}$ cells is associated with Abl kinase deficiency

Graphs of tumor cell growth (photon flux [photons/s]) for Abl family kinase-deficient (ABL KD, ARG KD, ABL/ARG KD) and non-targeting (NT/NT) mCRPC cells growing under (A) 3D and (B) standard (STD) conditions for seven days. Bars indicate mean +/- SEM for 6 wells/cell type/condition. ${ }^{* * *}$ and ${ }^{* * * *}$ denote statistically significant $p$-values of $<0.001$ and $<0.0001$, respectively, and n.s. stands for not significant. One-way ANOVA with Sidak multiple comparison test, $\alpha=0.05$. Immunoblot analysis of AKT phosphorylated on serine 473 (pAKT S473), total AKT (AKT), and an a-tubulin loading control for Abl family kinase-deficient and nontargeting mCRPC cells growing under (C) 3D and (D) STD conditions for 4 days. 
Figure 5: Loss of Abl family kinase activity preferentially enhances the 3D growth of androgen receptor (AR) indifferent prostate tumor cell lines

Graphs of (A) tumor cell growth (photon flux [photons/s]) and (B) fold change in tumor cell growth relative to vehicle for Abl family kinase-deficient ( $A B L K D, A R G K D$, and ABL/ARG KD) and non-targeting (NT/NT) mCRPC cells growing in 3D and treated with DMSO (white), 3 uM imatinib (light gray), or 10 uM imatinib (black) for 7 days. Bars in A \& B indicate mean +/- SEM for 6 wells/cell type/condition. ${ }^{* * *}$ in A. indicates statistically significant $p$-values $<0.0001$ within each cell type for a specific dose of imatinib relative to DMSO control. Unpaired t-test with Holm-Sidak correction for multiple t-tests, $\alpha=0.05 .{ }^{* * *}$ and ${ }^{* * * *}$ in B. denote statistically significant $p$-values of $<0.001$ and $<0.0001$, respectively, for each Abl family kinase-deficient cell type relative to NT/NT cells for a specific dose of imatinib. Two-way ANOVA with Sidak multiple comparison test, $\alpha=0.05$. (C) Immunoblot analysis of AKT phosphorylated on serine 473 (pAKT S473), total AKT (AKT), and an a-tubulin loading control for Abl family kinasedeficient and non-targeting MCRPC cells growing in 3D and treated with DMSO or 3 uM imatinib for 4 days. (D) Graph of fold change in growth relative to vehicle for AR-indifferent (black) and AR-driven (light gray) prostate cancer cell lines growing in 3D conditions with 3 uM imatinib. Bars indicate mean +/- SEM for 6 wells/cell line. ANOVA with Turkey's post-test, $\alpha=0.05$.

Figure 6: The AKT inhibitor, MK-2206, abolishes the increased 3D growth and AKT activation of Abl family kinase-deficient mCRPC cells

Graphs of tumor cell growth (photon flux in [photons/s]) for Abl family kinase-deficient (ABL KD, ARG KD, ABL/ARG KD) and non-targeting (NT/NT) mCRPC cells under 3D (A) and standard (C) conditions and treated with DMSO (white), 0.1 uM MK-2206 (light gray), 0.3 uM MK-2206 (dark gray), or 1.0 uM MK-2206 (black) for 7 days. Bars in A \& C indicate mean +/- SEM for 6 wells/cell type/condition. ${ }^{* * * *}$ in A signifies statistically significant $p$-values $<0.0001$. Unpaired $t-$ test with Holm-Sidak correction for multiple t-tests, $\alpha=0.05$. (B) Immunoblot analysis of AKT 
phosphorylated on serine 473 (pAKT S473), total AKT (AKT), and an a-tubulin loading control for Abl family kinase-deficient and non-targeting mCRPC cells growing in 3D for 4 days and treated with DMSO or 1.0 uM MK-2206 for 1 day.

\section{Figure 7: Reverse phase protein array (RPPA) analysis of Abl family kinase-deficient} mCRPC cells growing in 3D

(A) Heatmap displaying median-centered, normalized $\log _{2}$ values of differentially expressed antigens (DEAs). Lysates of NT/NT and ABL/ARG KD mCRPC cells grown under 3D conditions for 4 days were analyzed by RPPA. Antibodies with average normalized linear fold changes > 1.2 or $<0.8$ were considered DEAs. Rows corresponding to pAKT S473 (black) and c-Abl (red) are marked with arrows. Tables of average normalized linear fold changes for selected groupings of DEAs: (B) AKT signaling components, (C) cell cycle factors, and (D) genes involved in lipogenesis and metabolism.

Figure 8: AXL activation and expression is associated with the 3D growth phenotype and AKT hyperactivity of Abl family kinase-deficient mCRPC cells

(A) Immunoblot analysis of AXL autophosphorylated on tyrosine 779 (pAXL Y779), total AXL $(A X L)$, and a-tubulin loading control for Abl family kinase-deficient (ABL KD, ARG KD, ABL/ARG KD) and non-targeting (NT/NT) mCRPC cells growing in 3D for 4 days. (B) Graph of tumor cell growth (photon flux [photons/s]) of Abl family kinase-deficient and non-targeting mCRPC cells growing in 3D and treated with DMSO (white), 2.5 uM (gray), or 5 uM (black) of the specific AXL inhibitor, R428 for 7 days. Bars indicate mean +/- SEM for 6 wells/cell type/condition. ${ }^{* * *}$ indicates statistically significant $p$-values $\leq 0.0001$. Unpaired t-test with Holm-Sidak correction for multiple t-tests, $\alpha=0.05$. (C) Immunoblot analysis of AKT phosphorylated on serine 473 (pAKT S473), total AKT (AKT), and an a-tubulin loading control 
bioRxiv preprint doi: https://doi.org/10.1101/2020.05.19.104679; this version posted May 21, 2020. The copyright holder for this preprint (which

was not certified by peer review) is the author/funder, who has granted bioRxiv a license to display the preprint in perpetuity. It is made available under aCC-BY-NC-ND 4.0 International license.

for Abl family kinase-deficient and non-targeting mCRPC cells growing in 3D for 4 days and treated with DMSO or 5 uM R428 for 1 day. 
A $=$
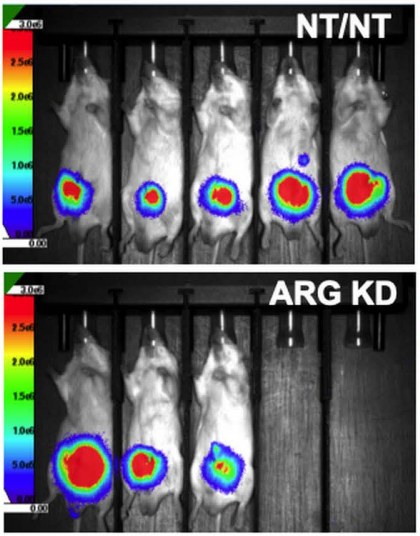

C

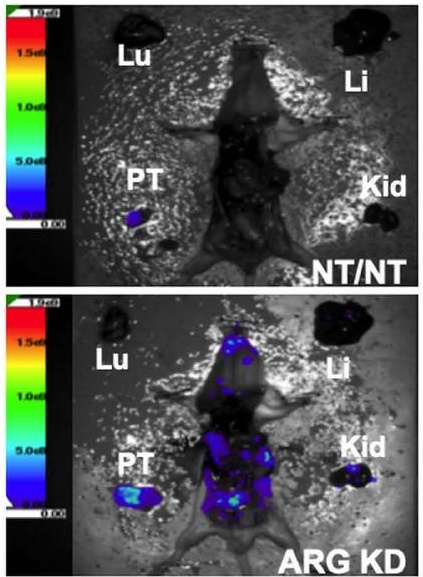

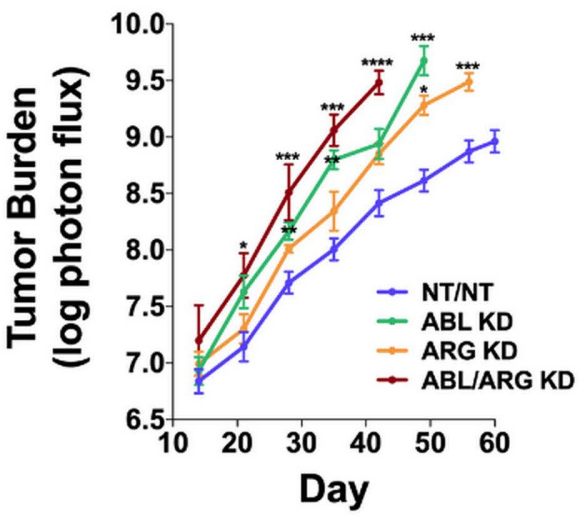

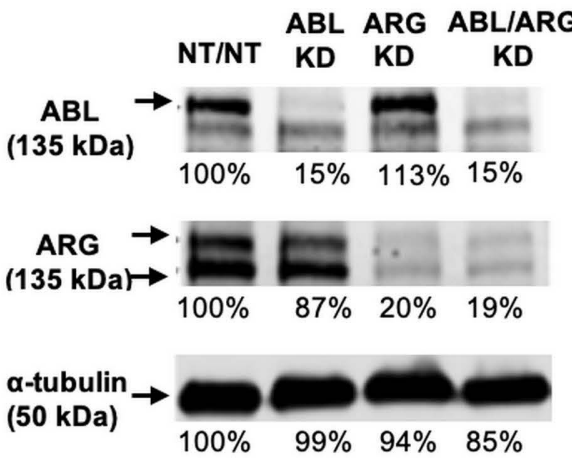

D

$\because$ ABL KD

$\because$ ARG KD

$\rightarrow$ ABLJARG KD Day

a-tubulin $100 \% \quad 99 \% \quad 94 \% \quad 85 \%$
ABL KD B

ABL KD B
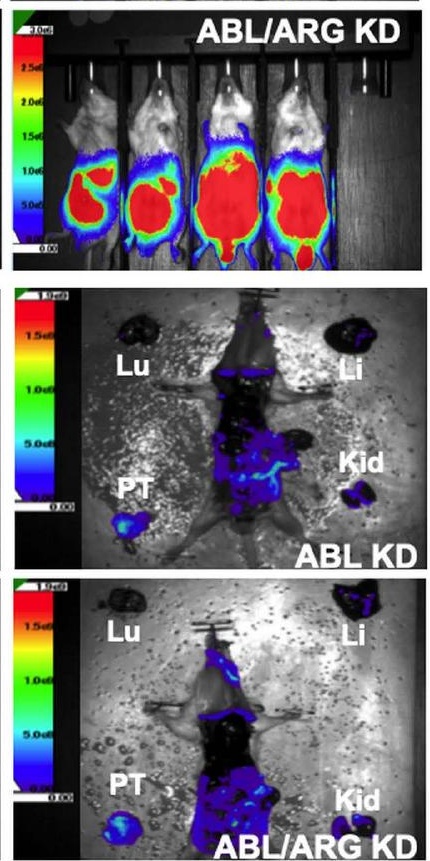


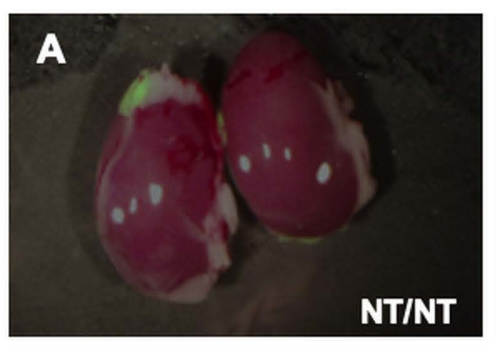

\section{B}

C

D

ABL KD

\section{E}
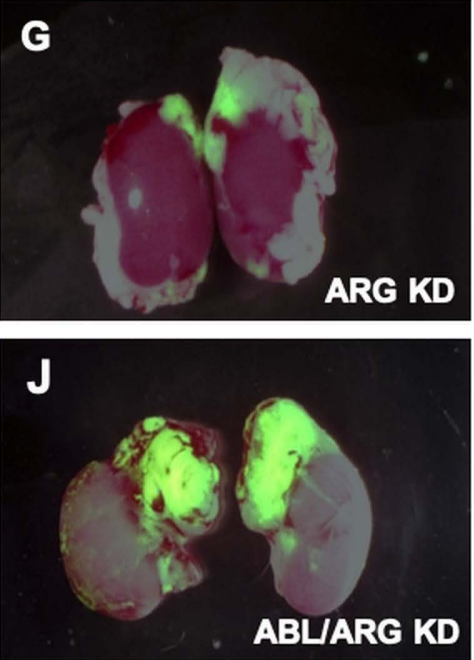

M

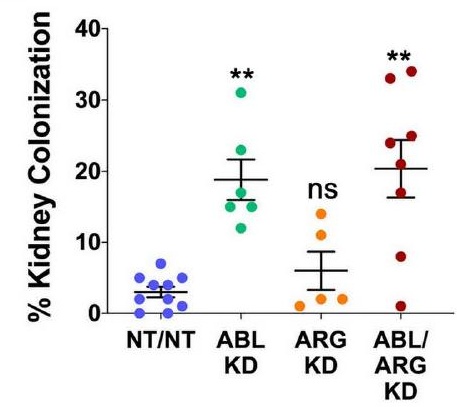

ABL KD

NT/NT

NT/NT

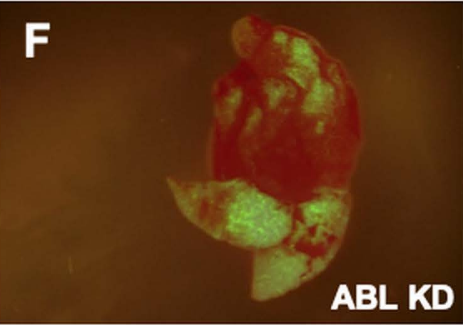

ARG KD

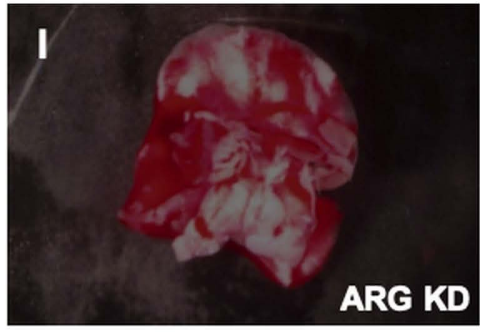

$\mathbf{L}$

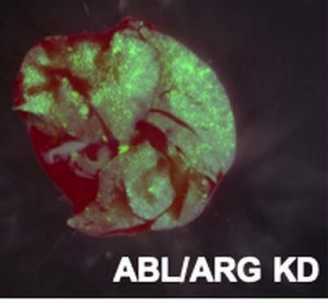

ABLARG KD

O

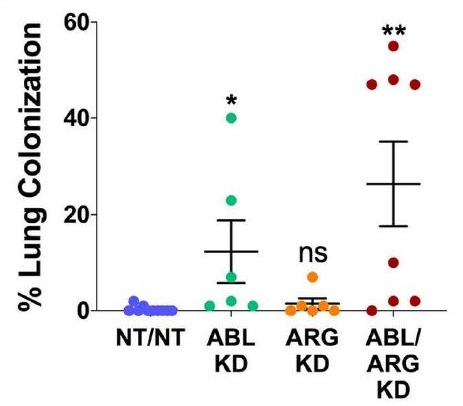


A

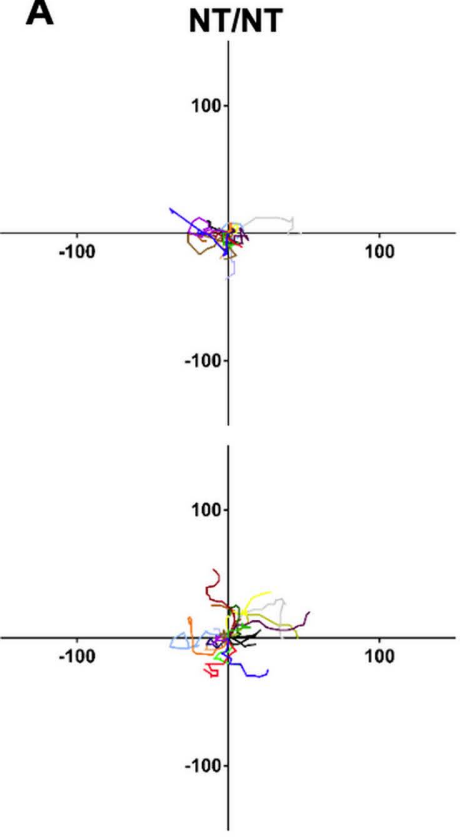

ARG KD
ABL KD

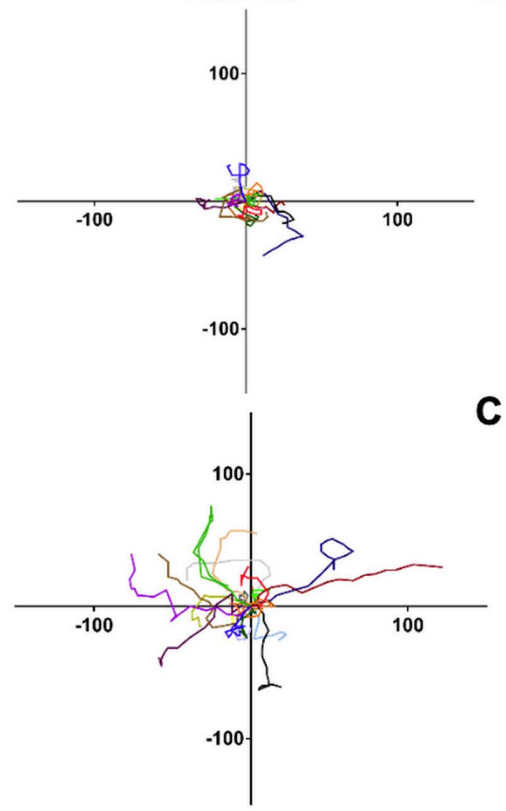

ABL/ARG KD

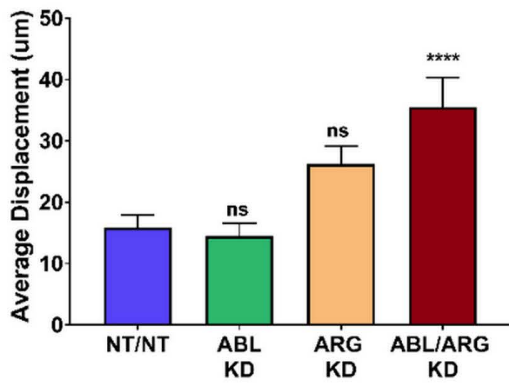



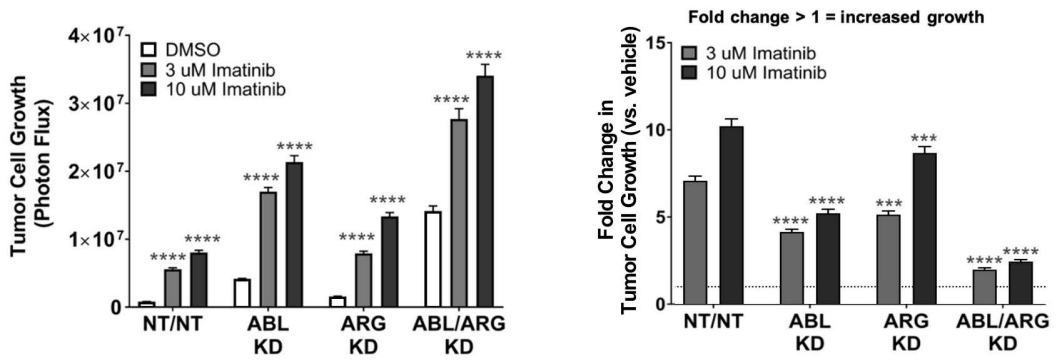

C

D
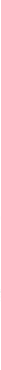


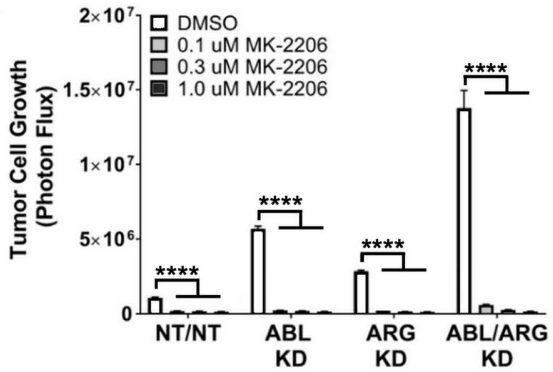

B

ABL ARG ABL/ARG ABL ARG ABL/ARG NT/NT KD KD KD NT/NT KD KD KD

PAKT S473 (60 kDa)

AKT $(60 \mathrm{kDa})$ a-tubulin (50 kDa)
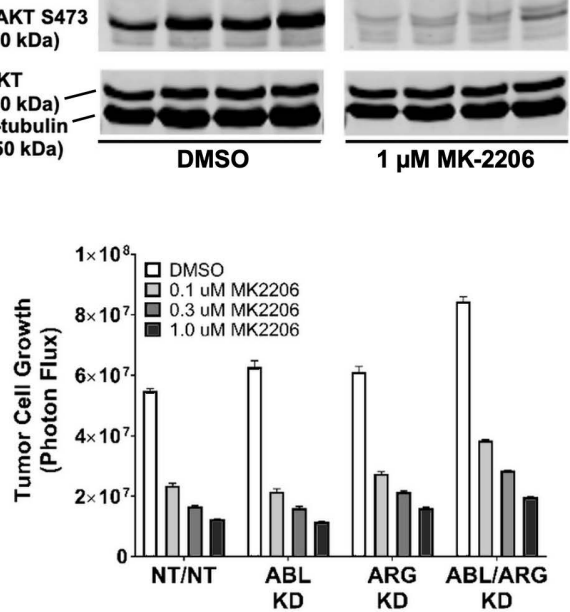
$\begin{array}{lll}-1 & 0 & 1\end{array}$

Row Z-Score

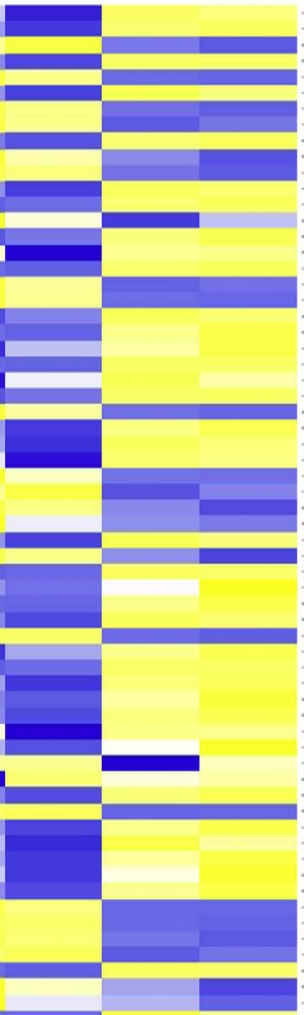

EIFAE.BP1

EIF4E.BP1_pS65

TP53BP1

- ACC1

Akt

Akt_pS473

AMPKa pT172

ATR_pS428

- Axl

- Bim

c.Abl

Caveolin.1

- code25C

- CDK1

- Collagen.VI

- Cyclin.B1

Cyclin.D3

DM. Histone. $\mathrm{H3}$

DM.K9. Histone.H3

- elF4G

- ER

- ERCC5

FASN

Fibronectin

G6PD

- Gab2

- GSK.3a.b

- GSK.3a.b_pS21_S9

HES1

Histone. $\mathrm{H} 3$

IGFRb

- IR.b

- LC3A.B

- IDHA

- LRP6.pS1490

- MERIT40_pS29

- Merlin

- MiG6

- Mnk1

MSI2

Myosin.lla p\$1943

NDRG1_pT346

- p21

- PAl.1

- PAICS

- PD.1

- PDK1

- PKA.a

- PKC.b.II_pS660

- PKCa

- Rab25

- Rb $\mathrm{Rb} 807$ _S811

- RIP

- S6

- \$6_p\$235\$\$236

- S6_pS240_\$244

- Smac

SOD2

- STING

- TFAM

- TSC1

- U.Histone.H2B

Vimentin

X BP.1

Canonical AKT Signaling Components

\begin{tabular}{|l|ll|}
\hline Gene Name & \multicolumn{2}{|l|}{$\begin{array}{l}\text { Average } \\
\text { RPPA Fold } \\
\text { Change }\end{array}$} \\
\hline 4E-BP1 pS65 & 1.3 & $\uparrow$ \\
\hline AKT pS473 & 1.5 & $\uparrow$ \\
\hline $\begin{array}{l}\text { GSK3 a/ } \\
\text { pS21/S9 }\end{array}$ & 1.2 & $\uparrow$ \\
\hline PDK1 & 1.2 & $\uparrow$ \\
\hline $\begin{array}{l}\text { pS6 } \\
\text { S240/244 }\end{array}$ & 1.4 & $\uparrow$ \\
\hline
\end{tabular}

Cell Cycle

\begin{tabular}{|l|ll|}
\hline Gene Name & $\begin{array}{l}\text { Average } \\
\text { RPPA Fold } \\
\text { Change }\end{array}$ \\
\hline CDC25c & 1.3 & $\uparrow$ \\
\hline Cyclin B1 & 1.5 & $\uparrow$ \\
\hline Cyclin D3 & 1.3 & $\uparrow$ \\
\hline $\mathrm{p} 21$ & 1.2 & $\uparrow$ \\
\hline $\begin{array}{l}\text { Rb } \\
\text { pS807/S811 }\end{array}$ & 1.2 & $\uparrow$ \\
\hline
\end{tabular}

Lipogenesis and Metabolism

\begin{tabular}{|l|ll|}
\hline Gene Name & $\begin{array}{l}\text { Average } \\
\text { RPPA Fold } \\
\text { Change }\end{array}$ \\
\hline ACC1 & 1.6 & $\uparrow$ \\
\hline $\begin{array}{l}\text { AMPKa } \\
\text { pT172 }\end{array}$ & 0.7 & $\downarrow$ \\
\hline FASN & 1.5 & $\uparrow$ \\
\hline G6PD & 1.5 & $\uparrow$ \\
\hline PAICS & 1.3 & $\uparrow$ \\
\hline
\end{tabular}



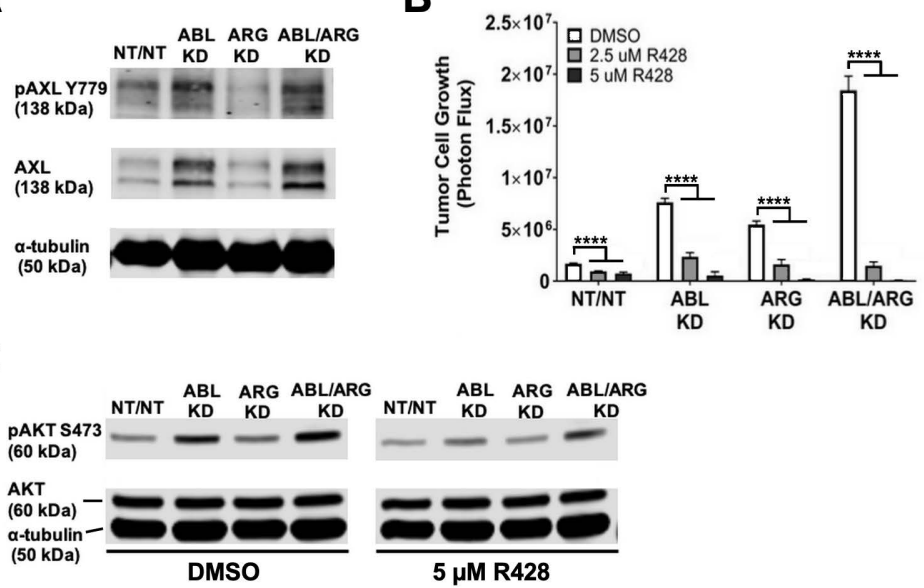

$5 \mu \mathrm{M}$ R428 